Check for updates

Cite this: RSC Adv., 2019, 9, 6254

Received 26th December 2018

Accepted 5th February 2019

DOI: $10.1039 / c 8 r a 10573 a$

rsc.li/rsc-advances

\title{
Surface hemocompatible modification of polysulfone membrane via covalently grafting acrylic acid and sulfonated hydroxypropyl chitosan
}

\begin{abstract}
Ming-Ming Tu, Jing-Jie Xu and Yun-Ren Qiu*
In this study, acrylic acid (AA) and sulfonated hydroxypropyl chitosan (SHPCS) were covalently grafted on the PSf membrane surface to improve its hemocompatibility. First, the modified AA-PSf membrane was obtained through the Friedel-Craft reaction between acrylic acid and the PSf membrane surface. Then, the modified SHPCS-AA-PSf membrane was prepared by grafting SHPCS onto the AA-PSf membrane surface via the dehydration acylation of the carboxyl group of the AA-PSf membrane with the amino group of SHPCS. ATR-FTIR and XPS measurements confirmed that the $-\mathrm{COOH}$ group and SHPCS were successfully grafted onto the surface of the PSf membrane. The modified PSf membranes showed suppressed platelet adhesion and lower protein adsorption $\left(161 \mu \mathrm{g} \mathrm{cm}^{-2}\right)$ compared with the pristine PSf membrane $\left(341 \mu \mathrm{g} \mathrm{cm}^{-2}\right.$ ). Hemocompatibility testing showed that modified membrane materials had a prolonged clotting time, plasma recalcification time (PRT), activated partial thromboplastin time (APTT), thrombin time (TT), and prothrombin time (PT). All of these results indicated that the surface modification of the PSf membrane with acrylic acid and SHPCS had good hemocompatibility and anticoagulant property.
\end{abstract}

\section{Introduction}

Polysulfone (PSf) membrane materials have been widely acknowledged and commercially used in many fields such as blood purification and hemodialysis over the last few years. ${ }^{1}$ $71 \%$ of hemodialysis membranes use PSf as materials, which had been investigated by the market data analysis of the Fresenius Medical Company in $2010 .^{2}$ Compared with the first generation of membrane materials such as cellulose and its ramifications, PSf, as a second-generation membrane material, has higher flux and can be more effective in the removal of "middle" molecules. ${ }^{3-5}$ Besides, PSf is widely used because of its great mechanical strength, thermal stability, chemical resistance, as well as its membrane-forming properties. ${ }^{6,7}$ Nevertheless, PSf material is hydrophobic by nature; when it is used as blood-contacting membranes, a series of bioresponses such as apparent protein adsorption, platelet adhesion, and the activation of the clotting enzyme will occur, which directly leads to thrombogenesis. ${ }^{8,9}$ Therefore, it is reasonable and necessary to modify pristine PSf to ameliorate its hemocompatibility.

Heparin, acknowledged as an effective anticoagulant agent, has been widely used to prevent the formation of coagulation and to improve the hemocompatibility of blood-contacting membranes. However, heparin treatment is expensive, which

College of Chemistry and Chemical Engineering, Central South University, Changsha 410083, PR China. E-mail: csu_tian@csu.edu.cn; Tel: +86-13507479124 may limit its large-scale use to some extent. ${ }^{10,11}$ Herein, numerous attempts have been focused on developing heparinmimicking materials or incorporating heparin-mimetic structures into membranes for the replacement of heparin to improve the hemocompatibility and tissue compatibility of the materials. ${ }^{12,13}$ Qin et al..$^{14}$ provided a highly efficient, convenient and universal protocol for the blood-compatible modification of polyethersulfone (PES) membranes via the in situ cross-linked copolymerization of 2-hydroxyethyl methacrylate (HEMA) and acrylic acid (AA) in PES solutions, and the results indicated that the modified membranes showed improved hydrophilicity, good blood anticoagulant and antifouling properties after grafting HEMA and AA. Kim et al. ${ }^{15}$ prepared sulfonated polyethersulfone by the heterogeneous method with chlorosulfonic acid; the modified membrane with a $-\mathrm{SO}_{3} \mathrm{H}$ group could reduce fouling and exhibited good blood compatibility. Lijing Zhu et al. ${ }^{16}$ fabricated PSf hemodiafiltration membranes by the in situ cross-linked polymerization of vinyl pyrrolidone (VP) and vinyltriethoxysilane (VTEOS) in PSf solutions and the nonsolvent induced phase separation (NIPS) technique. Ran et al. ${ }^{17}$ used vinyl pyrrolidone (VP) and methyl methacrylate (MMA) to modify the PES membrane via the blending method, and the blood compatibility, ultrafiltration and antifouling properties of the biomaterials were improved.

A lot of work have been done in terms of fabricating the modified membrane by grafting heparin-mimicking or heparinlike polymeric materials, which contain functional polar groups such as the hydroxyl group $(-\mathrm{OH})$, carboxyl group $(-\mathrm{COOH})$ and 
the sulfonic acid group $\left(-\mathrm{SO}_{3} \mathrm{H}\right),{ }^{18-20}$ onto membrane surfaces. This could be considered as an effective way to improve hemocompatibility, as these materials have similar specific functional groups to heparin. ${ }^{21}$ Among these modified methods such as coating, blending, grafting, in situ cross-linked copolymerization and layer-by-layer assembly methods, ${ }^{22-24}$ grafting is commonly considered as a useful and stable method compared with other methods. Chitosan (CS) has both amino and hydroxyl groups and has been identified as a non-toxic, biodegradable, cell compatible and biocompatible material. ${ }^{25-27}$ Yang et $a .^{28}$ grafted CS oligomer onto the polysulfone membrane via ozone-treatment, and COS-coupled PSf membranes showed a stronger biocidal effect for bacteria than untreated PSf membranes. Filiz et al. ${ }^{29}$ synthesized and modified PU via covalent immobilization of CS to improve its antibacterial properties. Liu et al. ${ }^{30}$ covalently immobilized citric acid (CA) and CS onto polyurethane (PU) materials followed by blending with PES; the modified membrane had good anticoagulant and antibacterial properties. Nowadays, CS has been utilized and exploited widely and deeply. M. Huo et $a .^{31}$ investigated the synthesis and anticoagulant activity of three different kinds of CS derivatives of similar structure including hydroxybutyl chitosan, hydroxypropyl chitosan sulfates, and quaternary ammonium chitosan sulfates. Fang et al. ${ }^{32}$ prepared sulfonated hydroxypropyl chitosan (SHPCS), which is a heparin-like material with excellent hemocompatibility. In our previous study, SHPCS was grafted onto the PSf membrane material by the Schiff-base reaction. The $-\mathrm{CH}_{2} \mathrm{Cl}$ groups were grafted onto PSf and then transformed into the PSf-Cl membrane through a phase-inversion technique, followed by immersion in ethylenediamine to introduce the amino, so that the sulfonated hydroxypropyl chitosan could be eventually grafted from the modified membrane with glutaraldehyde as the "bridge". ${ }^{33}$ However, the operation conditions are not moderate, and the synthesis process is time-consuming and complicated. Therefore, developing an efficient way to modify the PSf membrane with heparin-mimicking SHPCS on a large-scale remains highly desirable. We proposed that acrylic acid (AA) was firstly grafted onto the PSf membrane surface, which could allow-COOH to further react with heparin-like SHPCS and improve the hemocompatibility of the membrane. Compared with the traditional Schiff-base reaction, the modification of the PSf membrane via covalently grafting acrylic acid and SHPCS is simpler and more straightforward.

In order to graft - $\mathrm{COOH}$ onto the PSf membrane, PSf was used as the base. Acrylic acid was grafted onto the membrane surface by a $\mathrm{F}-\mathrm{C}$ reaction between PSf membrane and acrylic acid, and the modified membrane was termed the AA-PSf membrane. Afterwards, the modified membrane (SHPCS-AAPSf) can be obtained by dehydration acylation of the carboxyl group of the AA-PSf membrane with the amino group of the SHPCS. Attenuated total reflection-Fourier transform infrared (ATR-FTIR) spectroscopy, XPS, scanning electron microscopy (SEM), and water contact angle (WCA) measurements were applied to confirm the chemical components, surface morphology, and hydrophilicity of the modified PSf membranes. The hemocompatibility of the modified membrane was investigated by measuring the contact angle (WCA) and blood compatibility (protein adsorption, platelet adhesion, plasma recalcification time (PRT), hemolysis, APTT, PT and TT).

\section{Methods}

\section{Materials}

Polysulfone (average $M_{\mathrm{n}}: 22000$ ) and tin(Iv) chloride were purchased from Sigma, USA. Chitosan (viscosity: 100-200 mPa s) with a degree of deacetylation of about 95\% was obtained from Aladdin Industrial Corporation. Sodium dodecyl sulfate (SDS), sodium hydroxide ( $\mathrm{NaOH}$; $\mathrm{AR})$, propylene oxide (AR), formamide (AR), bovine serum albumin (BSA; AR) and sodium chloride (AR) were purchased from the Sinopharm Chemical Reagent Company, China. $N, N$-Dimethylacetamide (DMAC) used as the solvent was obtained from the Guangdong Guanghua Sci-Tech Company, China. Isopropanol (AR) and acetone were purchased from the Chengdu Kelong Chemical Reagent Company, China. Chlorosulfonic acid (CP) was acquired from Beijing Mashi Fine Chemicals Company, China. The MD44 dialysis bag (diameter: $28 \mathrm{~mm}$; molecular weight cut-off: 8000 dalton) was purchased from the Shanghai Leibusi Company.

\section{Modification of the PSf membrane}

PSf membrane was modified using acrylic acid. PSf flat-sheet membranes were prepared according to the method described by Xin Tian et al. ${ }^{34}$ The $18 \mathrm{wt} \%$ PSf was solved in the DMAC solvent with oscillation until a clear homogeneous solution was obtained. Afterward, the mixture was placed down to get rid of any bubbles at ambient temperature, cast onto a glass plate waiting for $10 \mathrm{~s}$ at room temperature, and then immersed in distilled water. The PSf flat-sheet membranes were obtained through the immersion precipitation phase inversion method and were cut into $1.0 \times 1.0 \mathrm{~cm}^{2}$ pieces for later use after being dried under vacuum (Fig. 1).

Firstly, the PSf flat-sheet membranes were washed with $\mathrm{NaOH}$ solution $\left(0.1 \mathrm{~mol} \mathrm{~L}^{-1}\right)$ and ultra-pure water. After being dried under vacuum, the PSf was subsequently incubated into a round-bottom flask containing acrylic acid $\left(14.5 \mathrm{~mol} \mathrm{~L}^{-1}\right)$. Simultaneously, $2.86 \mathrm{~g}$ of tin tetrachloride and $5 \mathrm{~mL}$ of phosphoric acid (19.2 $\mathrm{mol} \mathrm{L}^{-1}$ ) were added as an activator under slight stirring at $35{ }^{\circ} \mathrm{C}$ for a certain amount of time $(30 \mathrm{~min}$, $45 \mathrm{~min}, 60 \mathrm{~min}$, $75 \mathrm{~min}, 90 \mathrm{~min}$ ). Thus, the carboxyl groups were introduced to the PSf surface via the Friedel-Crafts alkylation reaction. In the end, the modified membranes grafted with acrylic acid, which were termed AA-PSf, were washed clearly with ultra-pure water to remove any unreacted substances. Furthermore, the surface grafting density of carboxyl groups was analyzed by the amount of toluidine blue $O$ (TB) dye adsorption. ${ }^{35}$ The carboxyl group on the membrane could form a complex with toluidine blue $\mathrm{O}$ (TB) dye at $\mathrm{pH} 10$; the complex dye molecules were then desorbed with $50 \mathrm{wt} \%$ acetic acid solution. Afterwards, the absorbance of the supernatant was determined at $633 \mathrm{~nm}$ by UV spectrophotometry. 

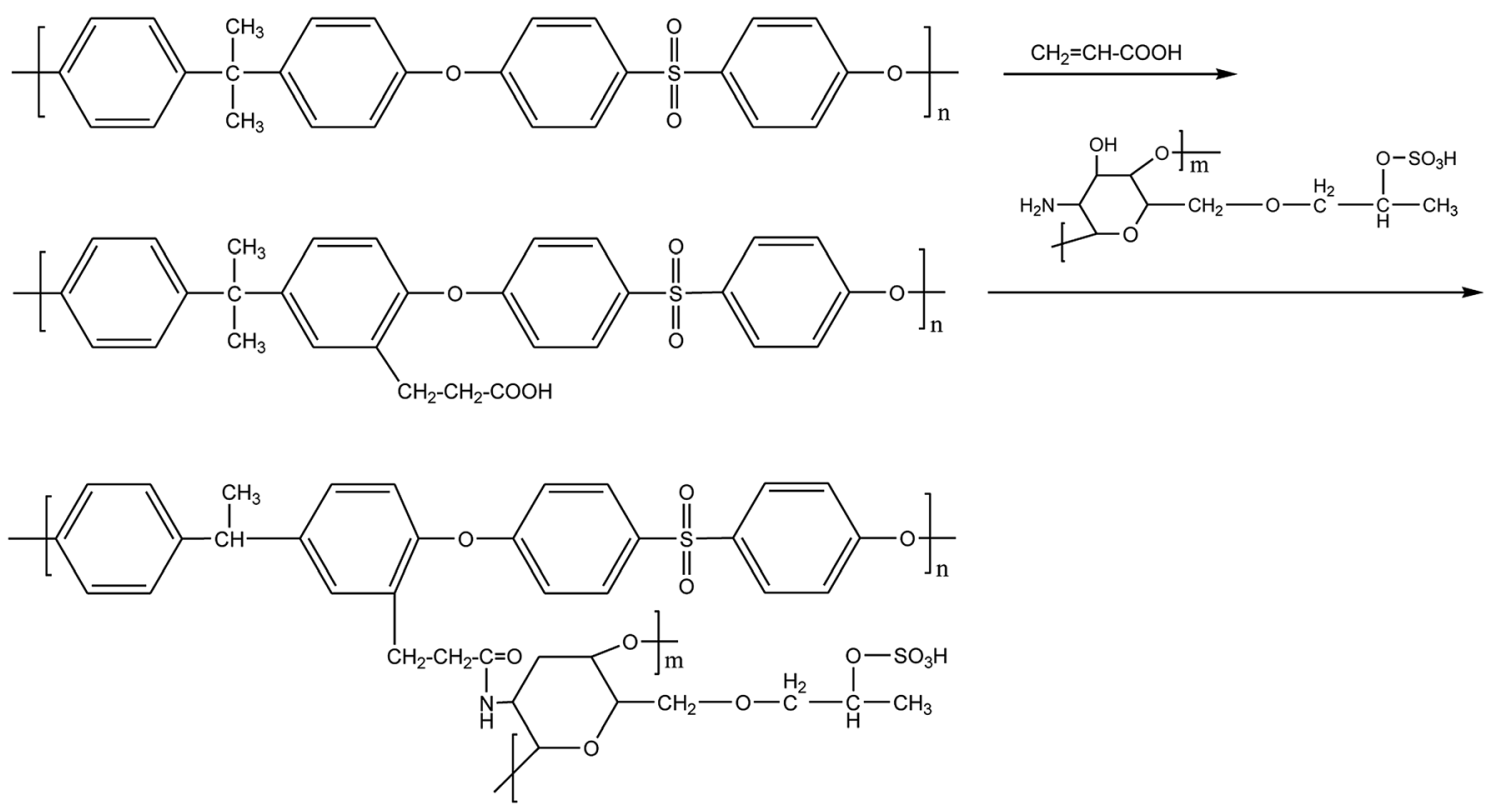

Fig. 1 The steps of the modification of the PSf membrane.

AA-PSf membrane was modified by SHPCS. These AA-PSf membranes were initially incubated in EDC solution $\left(0.01 \mathrm{~mol} \mathrm{~L}^{-1}\right)$ and citric acid buffer at $4{ }^{\circ} \mathrm{C}$ for $24 \mathrm{~h}$. Then, the membranes were immersed in $25 \mathrm{~mL}$ of SHPCS solution with a few drops of acetic acid at $25{ }^{\circ} \mathrm{C}$ for a certain number of hours (five groups: $1 \mathrm{~h}, 3 \mathrm{~h}, 7 \mathrm{~h}, 11 \mathrm{~h}, 15 \mathrm{~h}, 18 \mathrm{~h}, 20 \mathrm{~h}$ ). It worth noting that SHPCS was synthesized as described in our previous study. ${ }^{33}$ After being washed several times with ultra-pure water and dried in a vacuum, the modified membranes grating with SHPCS, which were termed SHPCS-AA-PSf, were finally obtained. The grafting yield $\left(\mathrm{mg} \mathrm{cm}^{-2}\right)$ was calculated as follows:

$$
\mathrm{GY}=\frac{m-m_{0}}{A}
$$

where GY $\left(\mathrm{mg} \mathrm{cm}^{-2}\right)$ is the grafting yield, $m_{0}(\mathrm{mg})$ and $m(\mathrm{mg})$ represent the weight of the dried membrane before and after grafting polymerization, respectively, and $A\left(\mathrm{~cm}^{2}\right)$ is the area of the membrane. All the results are the average values.

\section{Characterization of the SHPCS-AA-PSf membrane}

The attenuated total reflectance-Fourier-transform infrared (ATR-FTIR) spectra for modifying the membrane surfaces were measured using a Fourier-transform infrared spectrometer (Nicolet6700, USA). Elemental analyses of the modified membranes were performed using an ESCALAB 250Xi XPS instrument (Thermo Scientific, USA). The hydrophilicity of the membrane surface was evaluated using a contact angle goniometer (JC-2000D1, China) equipped with video capture on the basis of contact angle measurement. For the static contact angle measurements, a total of $3 \mu \mathrm{l}$ of distilled water was dropped on the air-side surface of the membrane at room temperature, and the contact angle was measured after $20 \mathrm{~s}$. At least five measurements were averaged to obtain a reliable value. A scanning electron microscope (SEM, JSM-IT300LA Japan) was used for the morphology observation of the membrane crosssections. All samples were dried overnight in a vacuum oven at room temperature and then quenched with liquid nitrogenous gas, attached to the sample supports and coated with a gold layer.

\section{Blood compatibility}

Protein adsorption. For the protein adsorption experiments, the method is similar to those described by Zhu et al. ${ }^{36}$ The membranes with an area of $1 \times 1 \mathrm{~cm}^{2}$ were incubated in phosphate buffer solution (PBS) for $24 \mathrm{~h}$ before use. Afterwards, the sample was immersed in the protein solution, which contains BSA and PBS ( $\mathrm{pH}=7.4$ ) with a concentration of $1 \mathrm{mg} / 1$ $\mathrm{mL}$, for $2 \mathrm{~h}$ at $37{ }^{\circ} \mathrm{C}$. Subsequently, the sample was rinsed slightly with PBS solution several times and then immersed in washing aqueous solutions (2 wt\% sodium dodecyl sulfate (SDS), $0.05 \mathrm{M} \mathrm{NaOH}, 37{ }^{\circ} \mathrm{C}$ with agitation for $2 \mathrm{~h}$ ) to remove the adsorbed protein. More than $95 \%$ of the adsorbed protein could be eluted into the SDS solution, and the amount of protein could be evaluated using the ultraviolet absorption method.

Platelet adhesion. This method is similar to those described by Zhang et al. ${ }^{37}$ Healthy fresh blood samples (man, 25 years old) were collected by vacuum tubes ( $2 \mathrm{~mL}$ G9NC2002, sodium citrate to blood ratio $1: 9$ ), which were centrifuged at $1000 \mathrm{rpm}$ for 15 min to obtain platelet-rich plasma (PRP). Then, the membrane $(1 \mathrm{~cm} \times 1 \mathrm{~cm})$ was immersed in PBS solution at $37{ }^{\circ} \mathrm{C}$ for $1 \mathrm{~h}$, followed by the removal of PBS solution, and the addition of $1 \mathrm{~mL}$ of fresh PRP. Next, the membrane was incubated in PRP at $37{ }^{\circ} \mathrm{C}$ for $2 \mathrm{~h}$ and subsequently rinsed slightly with PBS solution three times. Afterward, the membrane was treated with $2.5 \mathrm{wt} \%$ glutaraldehyde in PBS solution at $4{ }^{\circ} \mathrm{C}$ for 1 day. After being washed with PBS solution, the sample was immersed through a series of graded alcohol-PBS solutions 
(0\%, 25\%, 50\%, 75\% and 100\%) and graded isoamyl acetatealcohol solutions $(25 \%, 50 \%, 75 \%$ and $100 \%)$ for $15 \mathrm{~min}$, respectively. Afterwards, the membrane was freeze-dried, and the adherent platelet on the membrane was observed by SEM.

Plasma recalcification time (PRT). The membrane $(1 \mathrm{~cm} \times 1$ $\mathrm{cm}$ ) was immersed in the PBS solution and equilibrated at $37{ }^{\circ} \mathrm{C}$ for $1 \mathrm{~h}$. Then, $0.5 \mathrm{~mL}$ of fresh PPP obtained by centrifugation at $3000 \mathrm{rpm}$ for $15 \mathrm{~min}$ was introduced and afterward incubated statically at $37{ }^{\circ} \mathrm{C}$. Subsequently, $0.5 \mathrm{~mL}$ of $25 \mathrm{mM} \mathrm{CaCl}_{2}$ aqueous solution was added, and the plasma solution was monitored for clotting by manually dipping a stainless-steel hook coated with silicone into the solution to detect fibrin threads. Clotting times were recorded at the first sign of fibrin formation on the hook. The test was repeated three times for each sample to obtain a reliable value.

Hemolysis assay. The membrane sample $(1 \mathrm{~cm} \times 1 \mathrm{~cm})$ was immersed in normal saline at $37^{\circ} \mathrm{C}$ for $1 \mathrm{~h}$ at first. The entirety of the blood was diluted with the addition of normal saline, and the dilute solution was introduced into the tube containing the membrane sample. Besides, positive and negative controls were prepared by adding $2 \mathrm{~mL}$ of blood to $12 \mathrm{~mL}$ of ultra-pure water and normal saline, respectively. After that, all the samples were equilibrated in dilute solutions at $37{ }^{\circ} \mathrm{C}$ for $3 \mathrm{~h}$ and then centrifuged at $500 \mathrm{~g}$ for $10 \mathrm{~min}$. The percent hemolysis was calculated by measuring the absorbance of the supernatant solution at $545 \mathrm{~nm}$ using a UV-vis spectrophotometer. The hemolysis ratio (HR) was calculated as follows:

$$
\mathrm{HR}=\frac{D_{\mathrm{t}}-D_{\mathrm{nc}}}{D_{\mathrm{pc}}-D_{\mathrm{nc}}} \times 100 \%
$$

where $D_{\mathrm{t}}$ is the absorbance of the test sample, $D_{\mathrm{nc}}$ is the absorbance of the negative control and $D_{\mathrm{pc}}$ is the absorbance of the positive control. ${ }^{33}$

APTT, PT and TT. The membrane $(1 \mathrm{~cm} \times 1 \mathrm{~cm})$ was washed with PBS three times and dried. Then, the sample was immersed in $1 \mathrm{~mL}$ of PPP at $37^{\circ} \mathrm{C}$ for $1 \mathrm{~h}$. The APTT, PT and TT were obtained by a fully automatic blood coagulation detector (CA-7000) in the Fourth Hospital of Changsha.

\section{Antibacterial tests}

Medium preparation and sterilization. Nutrient broth liquid medium and nutrient agar solid medium were prepared separately. Afterwards, the medium, PBS, and all equipment used for the antibacterial experiments were placed in an autoclave, sterilized at $121{ }^{\circ} \mathrm{C}$ for $20 \mathrm{~min}$, and stored in a clean bench. At the same time, the nutrient agar solid medium was cooled to about $50{ }^{\circ} \mathrm{C}$, and an appropriate amount of liquid was evenly poured into the culture dish to prepare a nutrient agar plate for use.

Antibacterial experiment. The Pseudomonas aeruginosa strain ( $P$. aeruginosa) was inoculated into a test tube containing $10 \mathrm{~mL}$ of nutrient broth liquid medium and cultured in a biochemical incubator at a temperature of $37{ }^{\circ} \mathrm{C}$ for $18-24 \mathrm{~h}$. After the bacteria were proliferated, the bacteria-containing liquid was dispensed into three centrifuge tubes and centrifuged at $3000 \mathrm{rpm}$ for $10 \mathrm{~min}$ in a centrifuge to precipitate the bacteria in
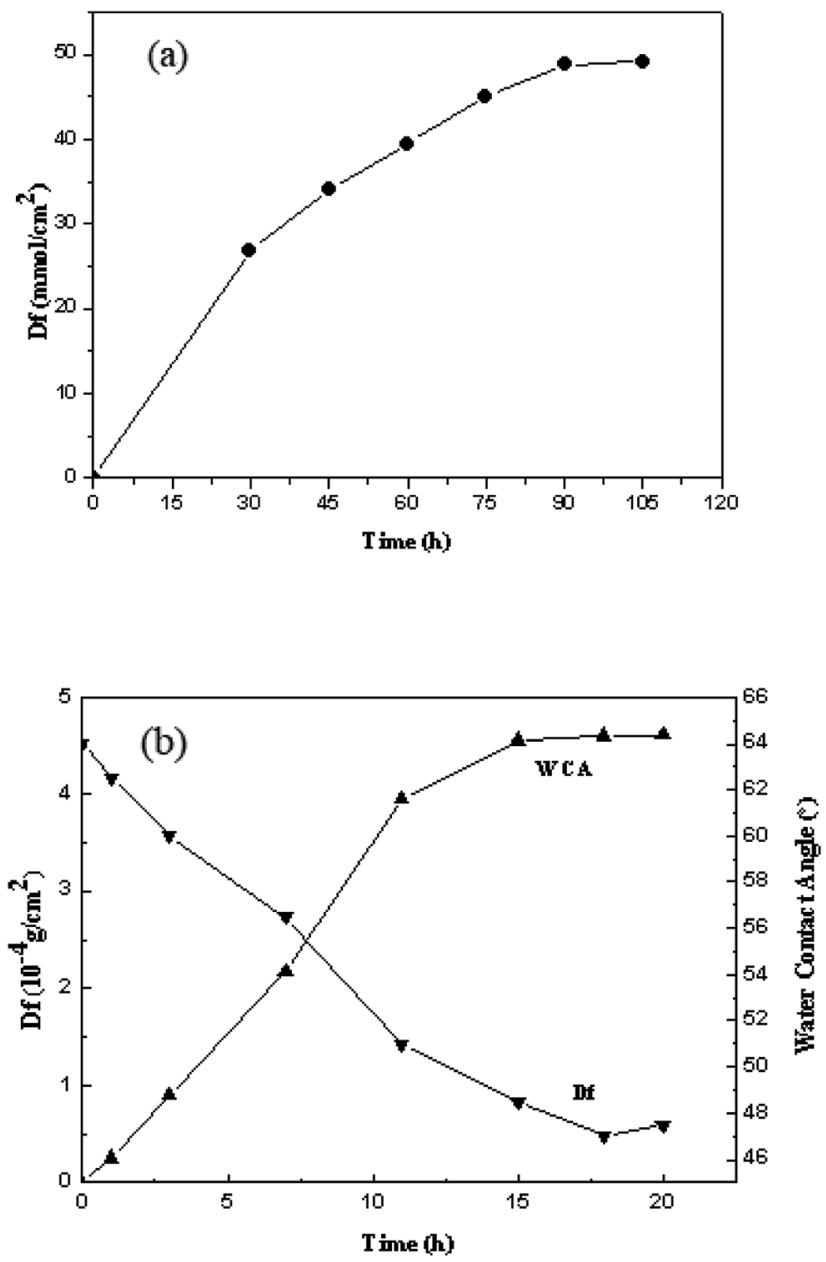

Fig. 2 The grafting density of acrylic acid at different reaction times (a); the grafting density of SHPCS and the SHPCS-AA-PSf water contact angle at different reaction times (b).

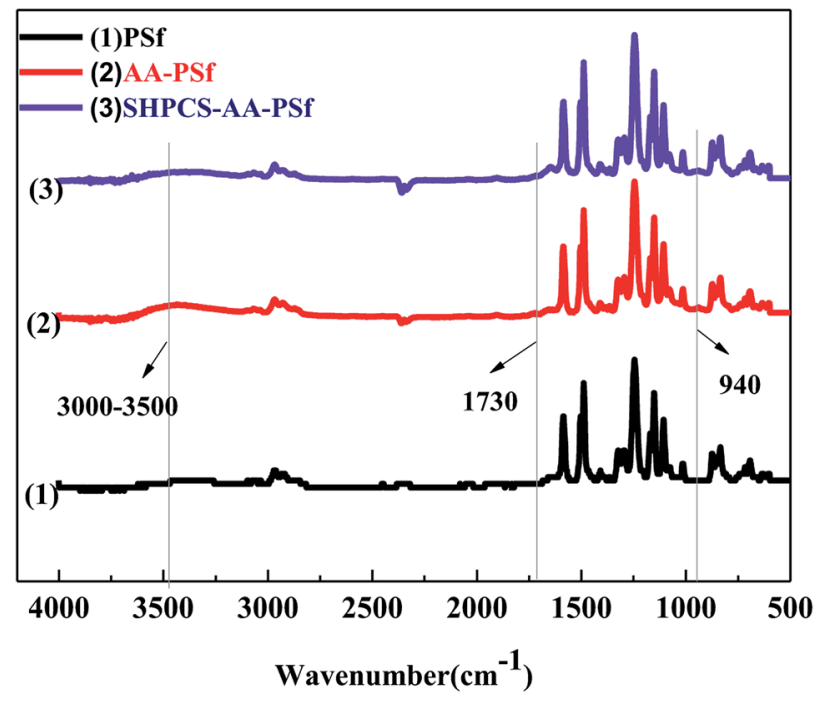

Fig. 3 ATR-FTIR spectra of PSf, AA-PSf and SHPCS-AA-PSf membranes. 
(a)
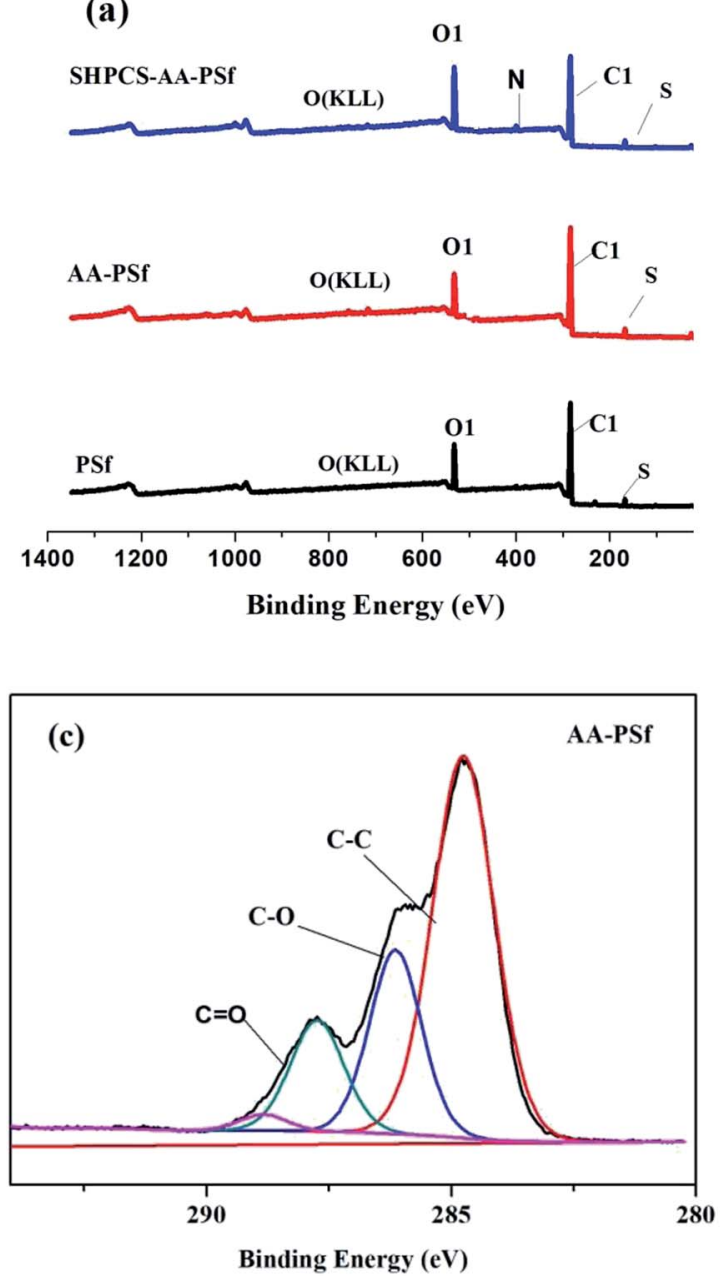
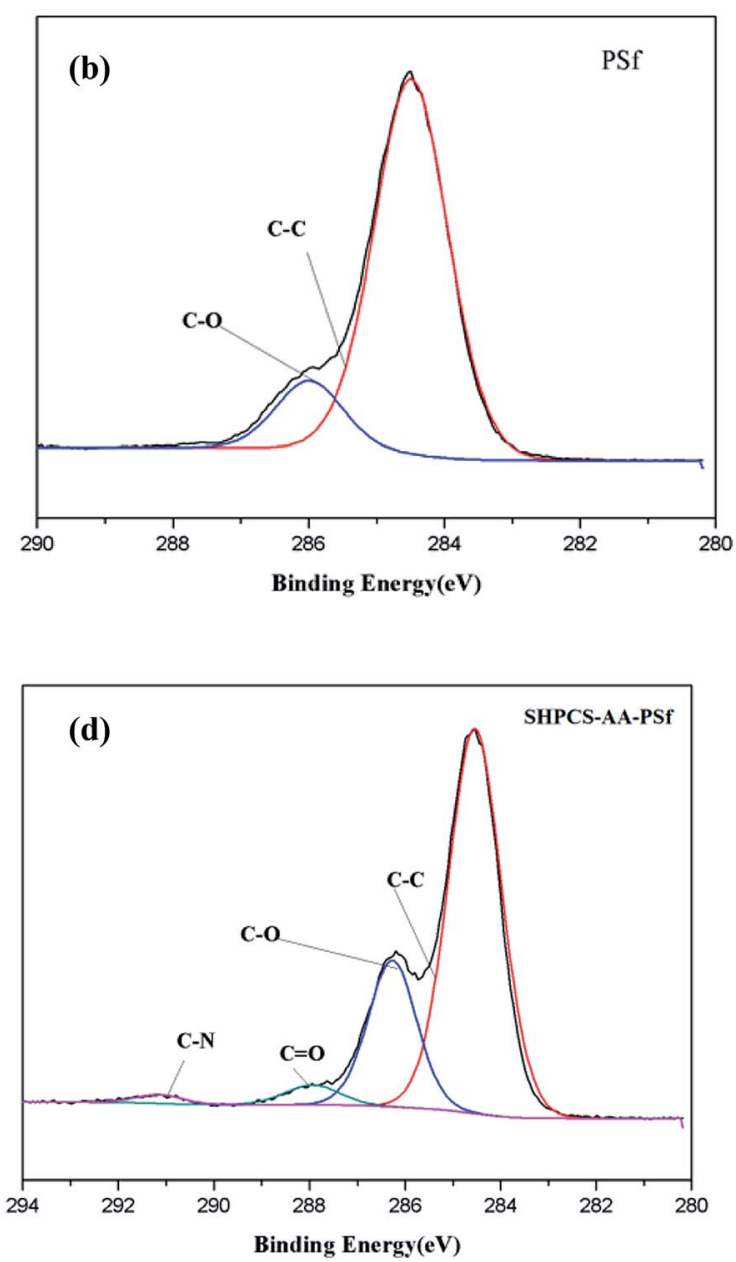

Fig. 4 XPS spectra of PSf, AA-PSf, and SHPCS-AA-PSf membranes (a); spectra analysis of the PSf membrane (b), AA-PSf membrane (c) and SHPCS-AA-PSf membrane (d).

the lower layer while removing nutrients from the bacterial liquid. The bacterial pellet was then washed twice with PBS, and the bacteria were suspended in $10 \mathrm{~mL}$ of PBS. $100 \mu \mathrm{L}$ of the bacterial suspension was placed on the surface of the PSf, AAPSf and SHPCS-AA-PSf membranes; $100 \mu \mathrm{L}$ of the bacterial suspension was placed in a centrifuge tube as the blank control group. Thereafter, all samples were placed in a biochemical incubator and incubated at $37{ }^{\circ} \mathrm{C}$ for $24 \mathrm{~h}$. Next, all patch samples were transferred to a centrifuge tube, and $1 \mathrm{~mL}$ of PBS was added to all centrifuge tubes. The bacterial suspension was serially diluted, $100 \mu \mathrm{L}$ of the dilution in each gradient was placed on a nutrient agar plate, and the bacterial solution was uniformly coated with a coating bar. Finally, all the nutrient agar plates were placed in a biochemical incubator at $18{ }^{\circ} \mathrm{C}$ for 18-24 $\mathrm{h}$, and the number of viable bacteria in the original bacteria solution was estimated by counting the number of colonies (CFU) formed.

\section{Live subject statement}

This study was performed with the approval of the Ethics Committee of Xiangya Medical College, Central South
Table 1 Elemental analysis of the PSf membrane and PSf-SHPCS membrane surfaces

\begin{tabular}{llllllll}
\hline & \multicolumn{1}{c}{$\mathrm{C}(\%)$} & & & & & & \\
\cline { 2 - 5 } Samples & $\mathrm{C}-\mathrm{C}$ & $\mathrm{C}-\mathrm{O}$ & $\mathrm{C}-\mathrm{N}$ & $\mathrm{C}=\mathrm{O}$ & $\mathrm{N}(\%)$ & $\mathrm{O}(\%)$ & $\mathrm{S}(\%)$ \\
\hline PSf & 68.53 & 12.33 & - & - & 0 & 16.57 & 2.57 \\
PSf-AA & 45.70 & 16.93 & - & 7.93 & 0 & 27.37 & 2.07 \\
PSf-SHPCS $_{\mathrm{b}}$ & 48.67 & 17.04 & 0.98 & 2.43 & 2.98 & 24.88 & 3.02
\end{tabular}

University, Changsha, China. All the experiments of blood compatibility were performed in accordance with the guidelines of the National Health Commission of China, and informed consent was obtained from all human participants in this study.

\section{Results and discussion}

PSf membrane was modified by acrylic acid and SHPCS

As showed in Fig. 2(a), the grafting density of acrylic acid increased with the reaction time, but the reaction speed decreased with the reaction time. When the time reached 

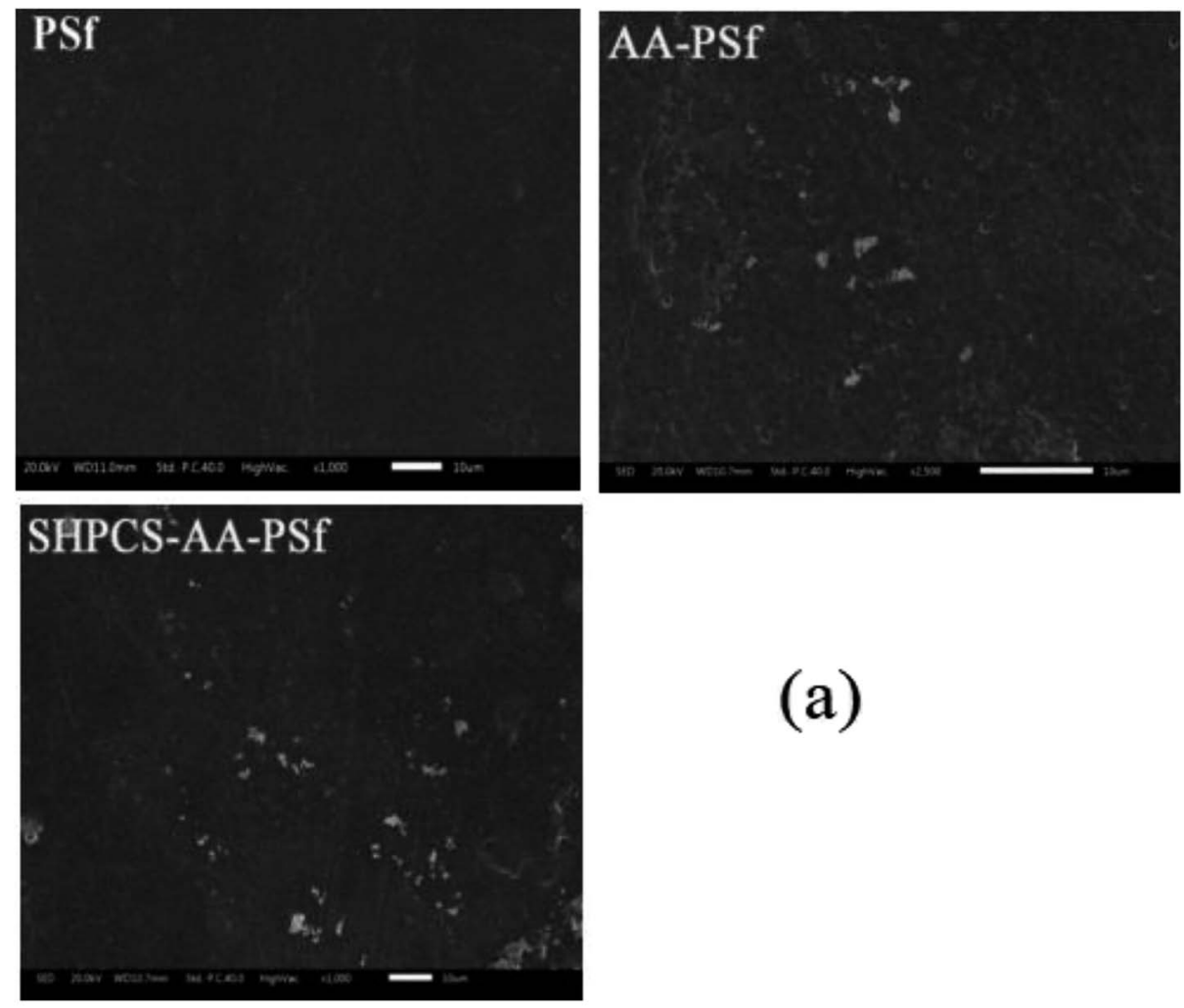

(a)
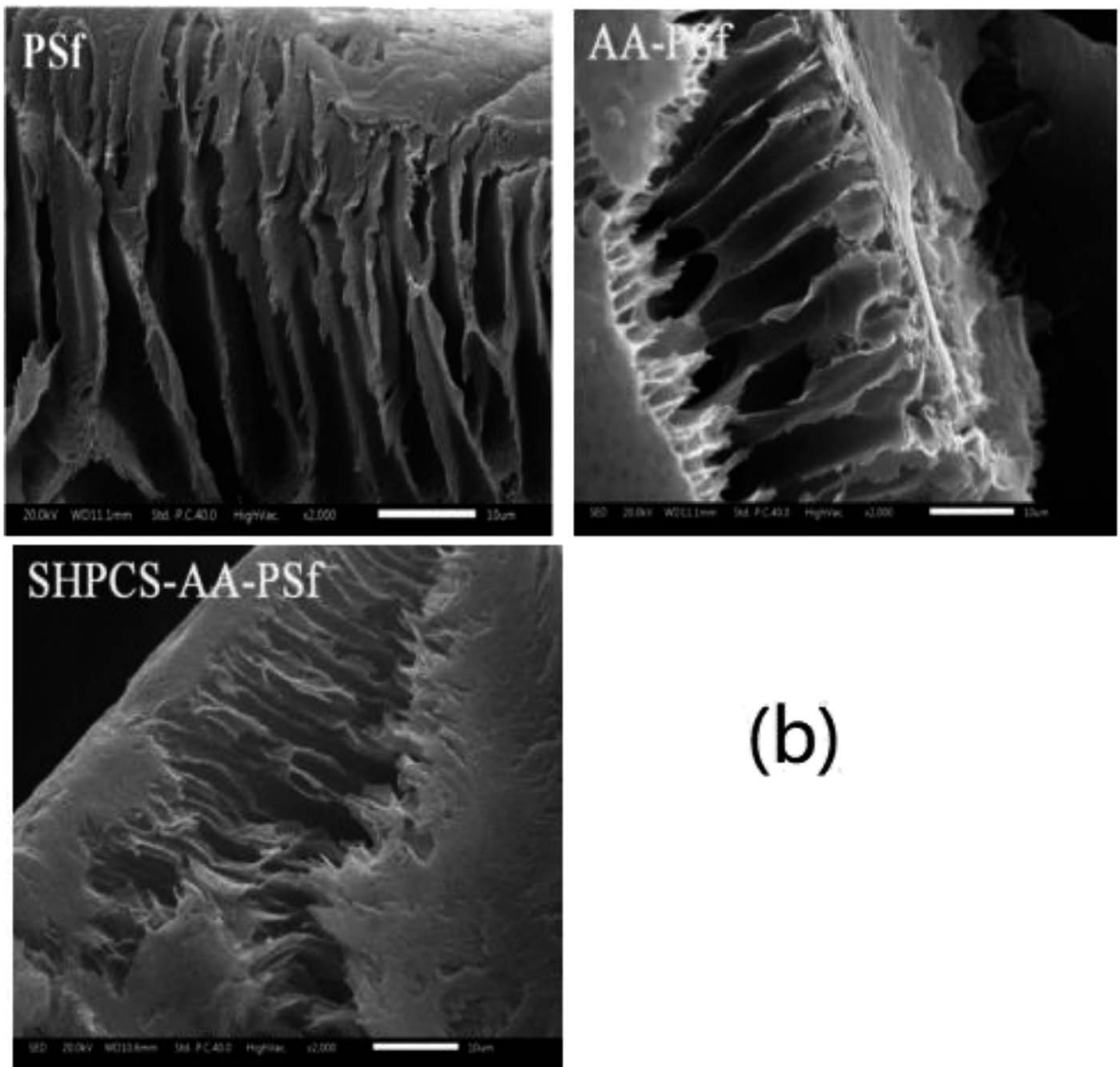

(b)

Fig. 5 SEM images of PSf, AA-PSf and SHPCS-AA-PSf membrane surfaces (a); SEM photographs of PSf, AA-PSf and SHPCS-AA-PSf membrane cross-sections (b). 



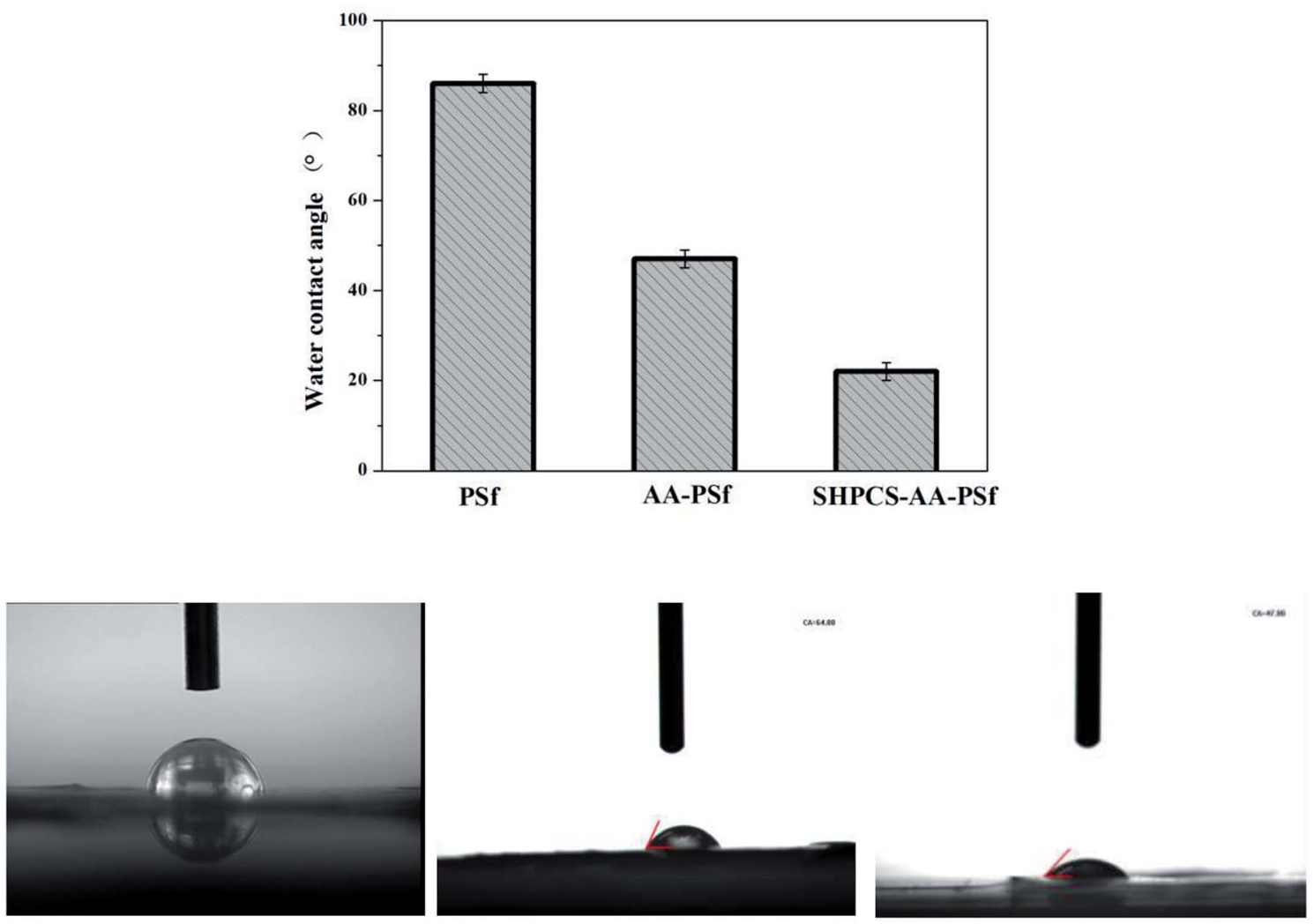

Fig. 6 Surface contact angles of the PSf membrane, AA-PSf membrane and SHPCS-AA-PSf membrane.

$90 \mathrm{~min}$, the greatest grafting density of $49.08 \mathrm{mmol} \mathrm{cm}^{-2}$ for acrylic acid was acquired. Nevertheless, the grafting density did not increase obviously from $90 \mathrm{~min}$ to $105 \mathrm{~min}$, and the results showed that $90 \mathrm{~min}$ was the most proper reaction time.

The effects of different reaction times on the grafting density of SHPCS and the hydrophilicity of the modified SHPCS-AA-PSf were investigated. According to Elimelech et al., ${ }^{38}$ the hydrophilic membrane can form a hydration layer on the surface and improve the antifouling performances. The water contact angle is a simple method to evaluate the hydrophilicity, which decreases with increasing hydrophilicity. As the reaction time continues to increase, the grafting density increased, and the contact angle of the membrane surface continuously decreases. The maximum grafting density of SHPCS reached $4.6 \times 10^{-4} \mathrm{~g}$ $\mathrm{cm}^{-2}$, and the grafting reaction nearly reached saturation. The water contact angle remained around $47^{\circ}$.

\section{Surface characterization}

ATR-FTIR analysis. ATR-FTIR spectroscopy was used to track any changes of the functional groups on the surface of membranes in the process of modification, and the results were shown in Fig. 3. Compared with the infrared spectrum of the original PSf membrane, the AA-PSf membrane was stronger near $1730 \mathrm{~cm}^{-1}$. A new absorption peak of the modified SHPCSAA-PSf appeared at $3500-3300 \mathrm{~cm}^{-1}$, which could be attributed to the characteristic peaks of the $-\mathrm{OH}$ and $\mathrm{N}-\mathrm{H}$ stretching vibrations, indicating that the acrylic material was successfully grafted onto the membrane material. Among them, the $-\mathrm{OH}$ group is likely to come from SHPCS used to modify the membrane. At the same time, the SHPCS-AA-PSf membrane has a strong peak at $940 \mathrm{~cm}^{-1}$, which belongs to the $\mathrm{C}-\mathrm{N}$ stretching signal, indicating that the $-\mathrm{NH}_{2}$ in SHPCS reacts with the oxidized PSf to form the amide bond. In addition, since the grafted material contains $\mathrm{S}=\mathrm{O}$, the signal of the modified membrane SHPCS-AA-PSf at the $1241 \mathrm{~cm}^{-1}$ signal of the $\mathrm{S}=\mathrm{O}$ stretching characteristic peak is stronger than the original PSf and AA-PSf membrane. It was concluded that SHPCS was covalently grafted onto the surface of the membrane.

XPS analysis. To further confirm whether acrylic acid was grafted onto the PSf membrane surface, and if SHPCS was introduced into the polysulfone membrane surface, XPS was used in this experiment to test the composition of chemical elements on the surface of the PSf membrane, AA-PSf membrane and SHPCS-AA-PSf membrane. The characterization results are shown in Fig. 4. The N1s signal peak of $399.58 \mathrm{eV}$ only appears at the SHPCS-AA-PSf, showing that SHPCS was grafted onto the surface of the PSf membrane.

From the C1s peak plots in Fig. 4, it can be seen that $\mathrm{C}=\mathrm{O}$ appears on the modified AA-PSf spectrum and $\mathrm{C}-\mathrm{N}$ and $\mathrm{C}=\mathrm{O}$ appear on the modified SHPCS-AA-PSf spectrum, which are consistent with the elemental analysis results presented in Table 1, Fig. 2 and 3. In the analysis of elemental content in Table 1, the $\mathrm{N}$ content in the original PSf membrane was 0 , and $\mathrm{C}-\mathrm{N}$ and $\mathrm{C}=\mathrm{O}$ did not appear. After the acrylic acid was grafted, $\mathrm{C}=\mathrm{O}$ appeared, and the content was $7.93 \%$. After modification 
(a)

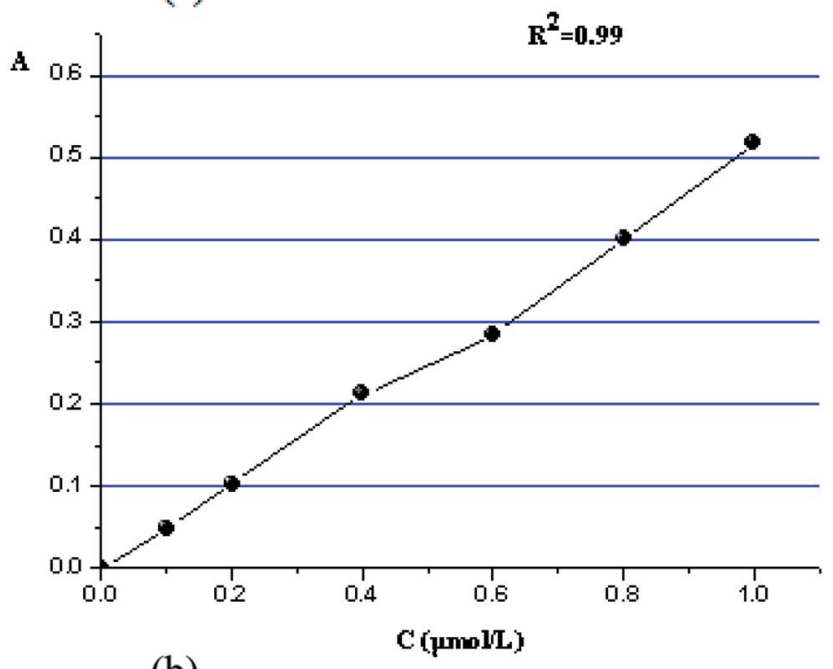

(b)

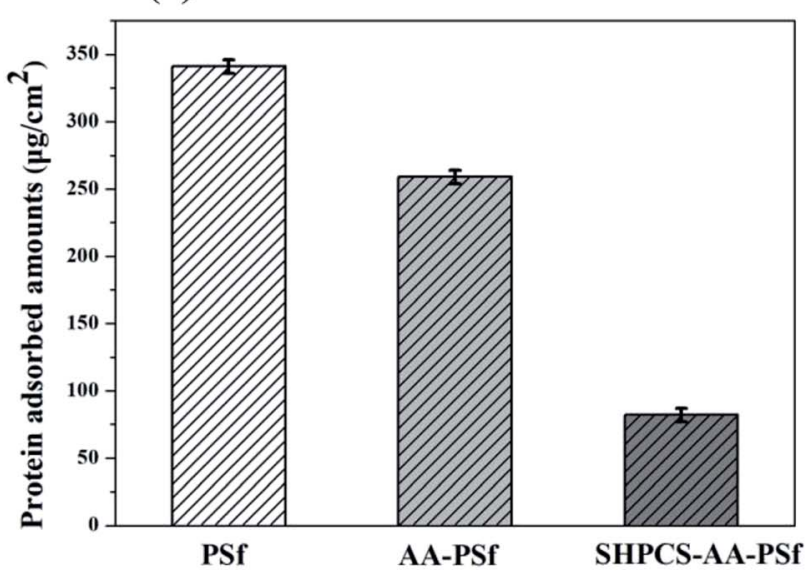

Fig. 7 The standard curve of BSA absorbance (a); the adsorption of BSA on PSf, AA-PSf and SHPCS-AA-PSf membranes (b).

by SHPCS, $\mathrm{C}-\mathrm{N}$ and $\mathrm{C}=\mathrm{O}$ appeared on the surface of the SHPCS-AA-PSf membrane material, the contents of which were $0.98 \%$ and $2.43 \%$, respectively, and the content of the $\mathrm{N}$ element also increased to $2.98 \%$. The $\mathrm{C}-\mathrm{C}$ content in the modified membrane SHPCS-AA-PSf decreased in comparison with $\mathrm{C}-\mathrm{C}$ in $\mathrm{PSf}$ which was $48.67 \%$, and the content of $\mathrm{C}=\mathrm{O}$ increased to $17.04 \%$. This is attributed to grafted SHPCS containing a large amount of $\mathrm{O}$ and $\mathrm{N}$ elements. Compared to the $2.57 \%$ of the $\mathrm{S}$ element before modification, the content of grafted SHPCS slightly increased to $3.02 \%$. We know that the synthesized SHPCS contains sulfonic acid groups and the $\mathrm{S}$ element of the membrane material. The increase may originate from SHPCS. These results clearly demonstrate that SHPCS had been successfully covalently grafted onto the PSf membrane surface.

The cross-section morphologies of membranes. The SEM images of cross sections of the PSf, AA-PSf and SHPCS-AA-PSf membranes were shown in Fig. 5. As discussed previously, the popularity of the PSf membrane results from its various excellent properties, especially the high permeability for lowmolecular-weight proteins, for the special morphology of the finger-like cross-sections consisting of a dense top-layer and porous sub-layer. It is worth noting that the surface SEM photograph clearly shows the change of the membrane surface from smooth material accumulation to the appearance of rough white micelles during the modification process, which is synchronous with changes in the properties of the membrane surface such as hydrophilicity. The asymmetric porous structure appeared in the cross-sectional SEM photographs of PSf, AA-PSf and SHPCS-AA-PSf membranes. Although the modification process increased the roughness of the membrane, the finger structure of the original unmodified PSf membrane was not subjected to major damage before and after modification.

Water contact angle analysis. Hydrophilic membrane materials have a high resistance to protein adsorption. The hydrophilic properties of the membrane during the modification process are determined by measuring the water contact angle on the surface of the membrane material. ${ }^{39}$ The results are shown in Fig. 6. The contact angle of the original PSf membrane was $86^{\circ}$. In comparison, the contact angle of the AA-PSf membrane grafted with acrylic acid decreased by $22^{\circ}$, indicating that the hydrophilicity of the membrane was somewhat improved. After grafting the highly hydrophilic heparinoid substance SHPCS, the contact angle of the modified membrane SHPCS-AA-PSf was significantly reduced to $47^{\circ}$, and the hydrophilicity change in this process can be clearly seen in Fig. 6 . After modification, the hydrophilicity of the membrane improved, and the performance against protein contamination can be expected to improve.

\section{Blood compatibility of the modified membranes}

Protein adsorption. When the blood comes into contact with the surface of the material, it could induce platelet adhesion and activation of various coagulation pathways, leading to coagulation..$^{40}$ Therefore, the amount of protein adsorption on the surface of the membrane is an important indicator of the blood compatibility of the membrane material. In this experiment, BSA was used to simulate the protein adsorption in vitro, for it has a similar molecular weight and Stokes radius to the human serum albumin. The results are shown in Fig. 7.

It can be seen that the modified AA-PSf and SHPCS-AA-PSf membranes were found to have lower BSA adsorption than the unmodified PSf membrane and that the amount of BSA adsorbed on the modified SHPCS-AA-PSf membrane is the lowest among the membranes. This may be because the SHPCSAA-PSf membrane has both a sulfonic acid group and a carboxyl group in the heparin structure, greatly improving the hydrophilicity and resistance to protein adsorption. These results are also consistent with those of the hydrophilicity of the membranes discussed in previous sections. These also indicate that the BSA adsorption amount of the modified membrane was reduced and that the anti-protein contamination performance of the modified membrane, especially the SHPCS-AA-PSf modified membrane, was greatly improved.

Platelet adhesion. The blood compatibility of the membrane material can be detected by performing an in vitro platelet adhesion test. After contacting the membrane material, on one 

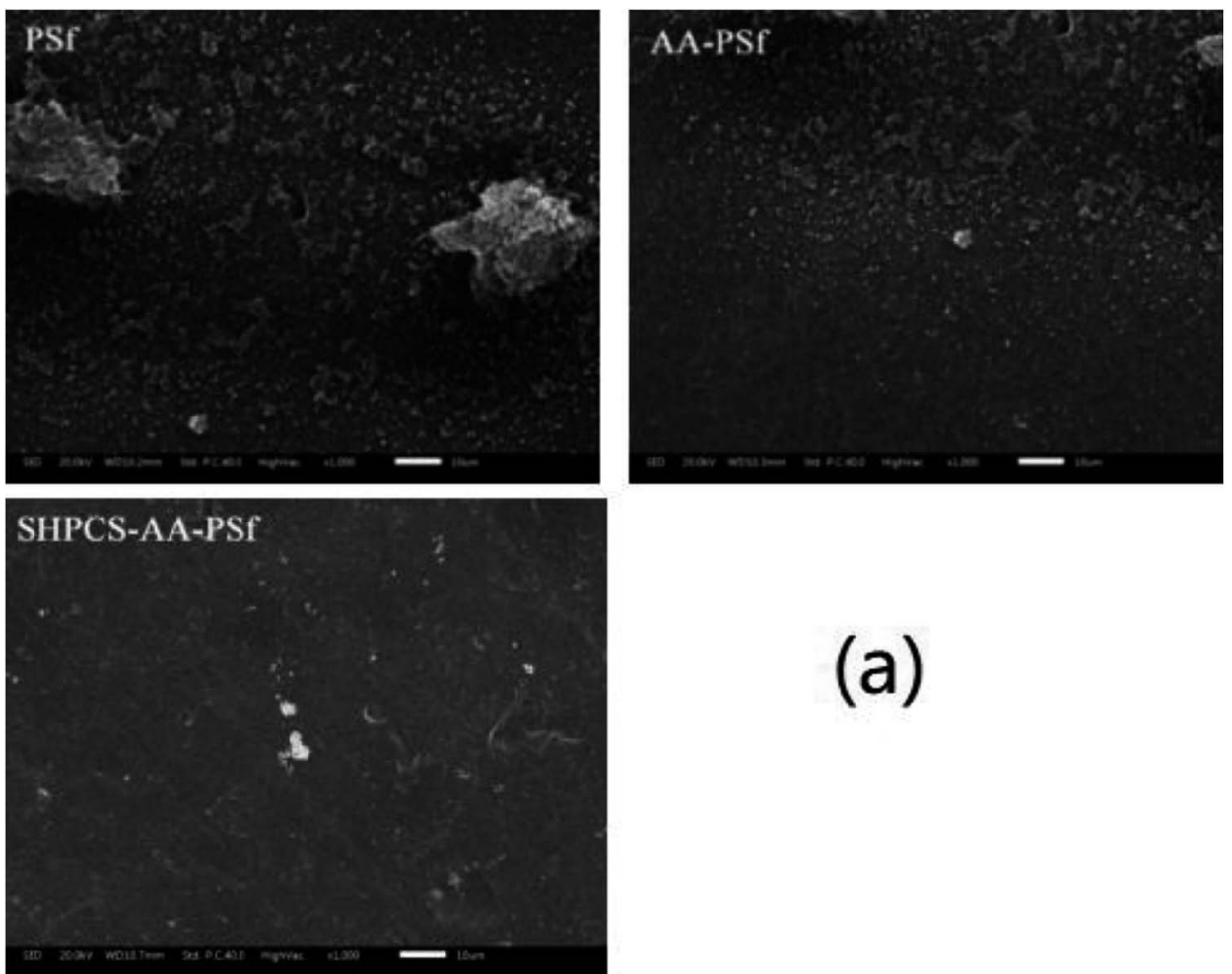

(a)
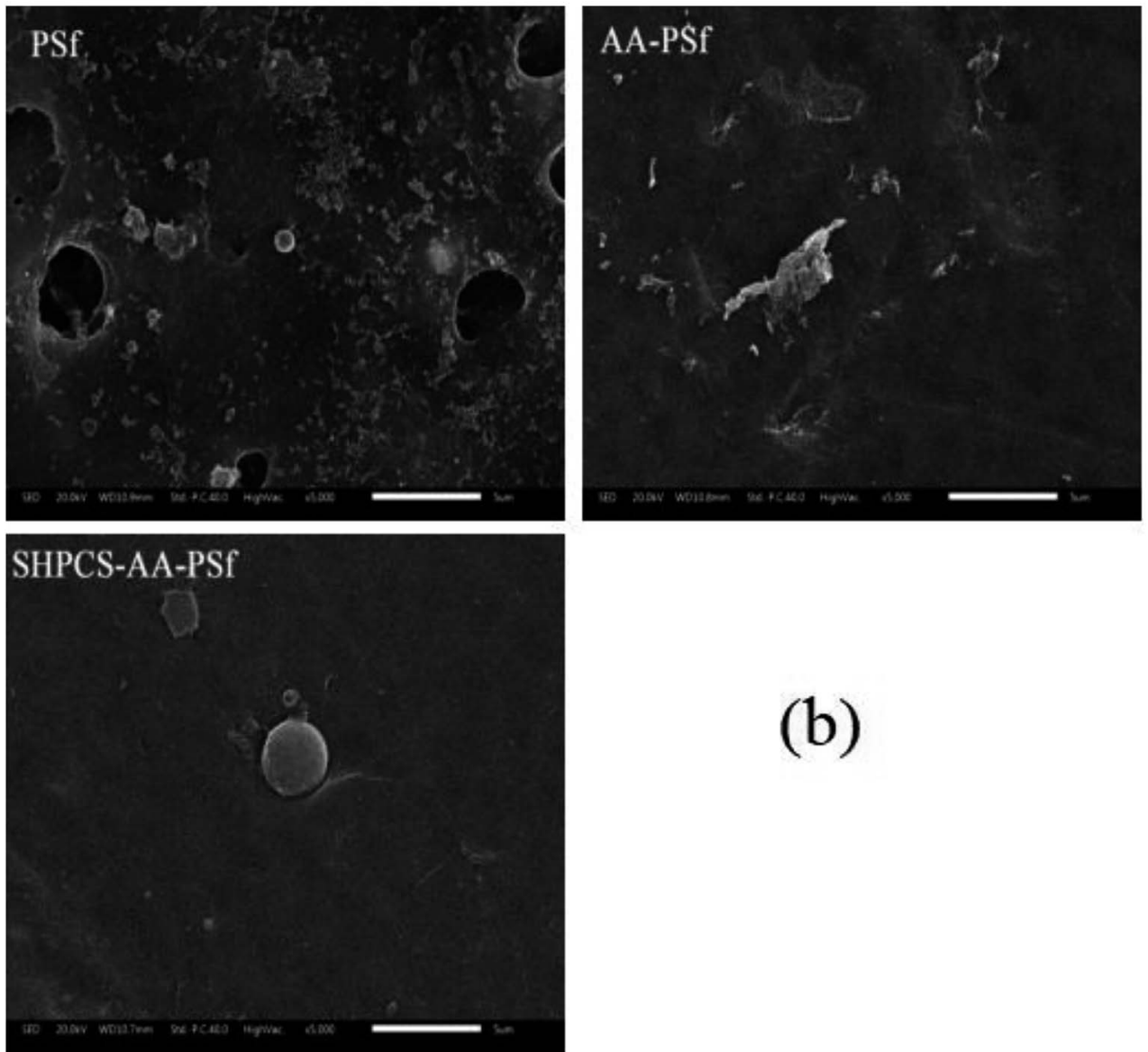

(b)

Fig. 8 The SEM image of platelets adsorbed onto PSf, AA-PSf and SHPCS-AA-PSf membranes. Magnification: 1000× (a); magnification: 5000× (b). 

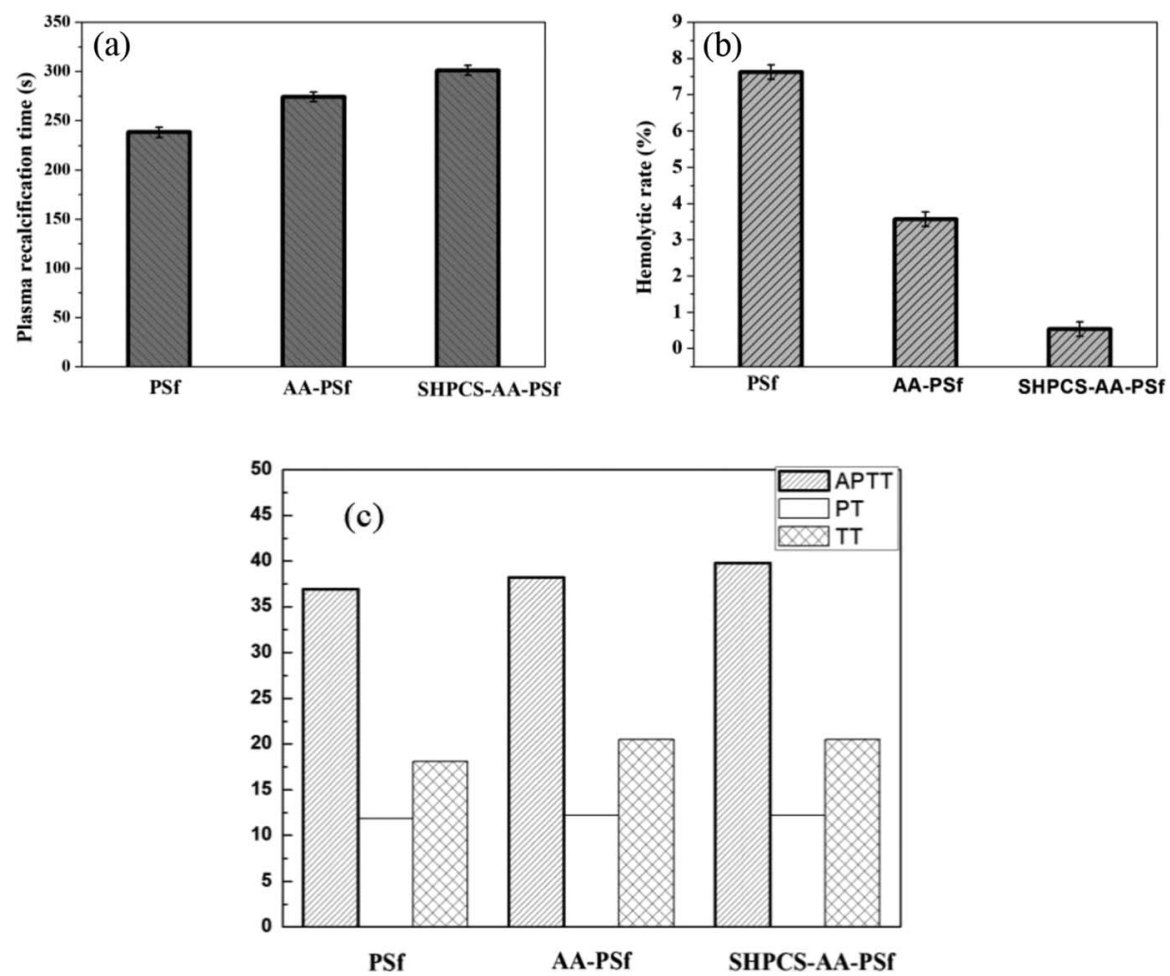

Fig. 9 The plasma recalcification time of PSf, AA-PSf and SHPCS-AA-PSf membranes (a); the hemolysis rate of PSf, AA-PSf and SHPCS-AA-PSf membranes (b); the APTT, PT and TT of PSf, AA-PSf and SHPCS-AA-PSf membranes (c).

hand, it adheres to the surface and activates to cause platelet aggregation. On the other hand, the activated platelets activate a variety of blood coagulation factors, causing coagulation on the surface of the membrane material. During this process, platelets accumulate and become flat or irregular in shape from the original circle, and a "pseudo-foot" extends around them. Therefore, we conducted scanning electron microscopy (SEM) of the number and shape of adherent platelets on the membranes (PSf, AA-PSf, and SHPCS-AA-PSf), and the results are shown in Fig. 8.

After 1000 scanning electron micrographs, it can be observed that a large amount of platelets accumulated on the original PSf membrane and appear irregularly arranged on the surface of the membrane. After grafting acrylic acid, the number of platelets can be seen to decrease, and after grafting SHPCS on the surface of the membrane, it was observed that the platelet distribution on the surface of the modified membrane was more dispersed and that the number of platelets decreased more than on the unmodified PSf membrane. The grafted SHPCS increased the blood compatibility of the material in terms of quantity and aggregation. In order to observe the morphology of the adhered platelets more clearly, 5000 SEM photographs were obtained. It can be observed from Fig. 7(b) that the platelets adhering to the surface of the PSf membrane have undergone irregular deformation and that the pseudopods have been extended. However, no deformation was observed on the surface of the SHPCS-AA-PSf membrane. This indicates that SHPCS plays a certain role in resisting platelet accumulation and deformation. These tests are consistent with BSA adsorption and other blood experiments, indicating a significant improvement in membrane blood compatibility after modification.

Plasma recalcification time (PRT). During endogenous coagulation, the activation of the coagulation factor XII causes a series of interactions between coagulation factors, resulting in the formation of thrombin by prothrombin. The plasma recalcification time (PRT) refers to the time required for calcium decalcification and calcium coagulation. It is often used to simulate endogenous coagulation processes in vitro, and the number of coagulation factors and anticoagulants affects plasma recalcification time (PRT). In order to further evaluate the anticoagulant properties of the modified membrane, we performed PRT tests on the original membrane and the modified membrane, and the results are shown in Fig. 9(a). It is not difficult to find that the plasma recalcification time of the PSf membrane is $238 \mathrm{~s}$. When the surface of the membrane is grafted with SHPCS, the plasma recalcification time of the SHPCS-AA-PSf membrane reached $301 \mathrm{~s}$. The change of PRT is obvious compared with the unmodified membrane. These results indicate that the modified membrane has a certain anticoagulant property.

Hemolysis assay. When red blood cells are damaged and release hemoglobin into the plasma, this phenomenon is called hemolysis. A large amount of hemolysis can directly induce coagulation, and the damage of the erythrocyte membrane may also cause platelet deformation and further lead to coagulation. Therefore, over the course of the experimental research, we used the hemolysis rate (HR) to evaluate the blood compatibility of the membrane materials. ${ }^{41}$ It can be seen from Fig. 9(b) that 

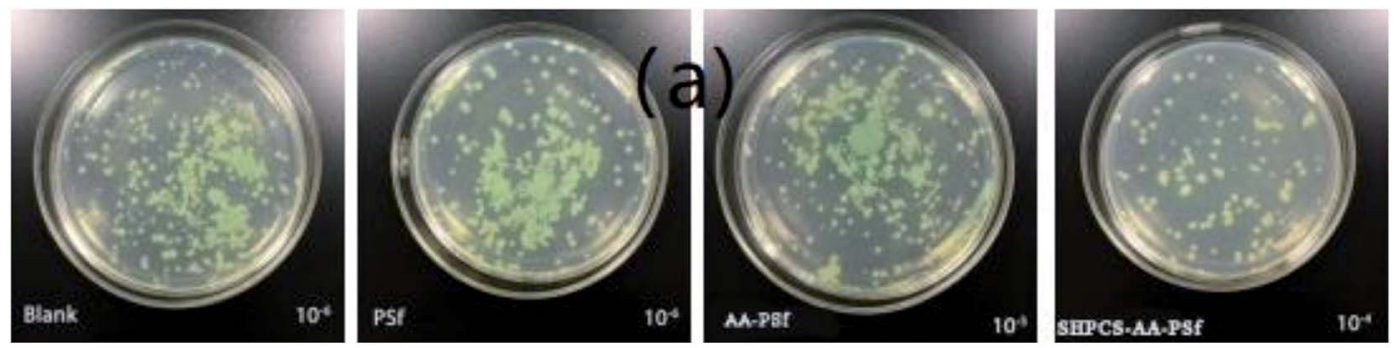

(b)

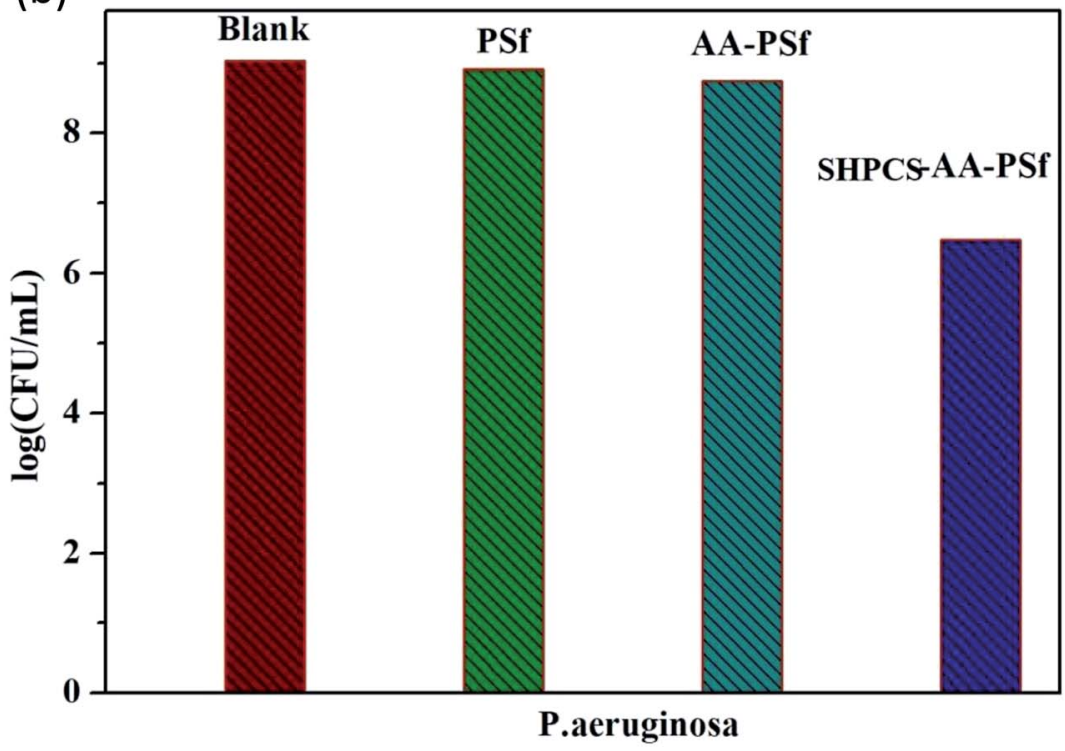

Fig. 10 Images of $P$. aeruginosa under different culture conditions (a); effects of blank, PSf, AA-PSf and SHPCS-AA-PSf membrane on the survival number of $P$. aeruginosa (b).

the hemolysis rate (HR) of the PSf membrane was $7.62 \%$. After the grafting of acrylic acid by the Friedel-Craft reaction, the hemolysis rate of the AA-PSf membrane was $3.57 \%$, which was lower than that of the unmodified PSf membrane. When SHPCS was grafted onto the surface of the membrane, the hemolysis rate (HR) of SHPCS-AA-PSf decreased sharply $0.53 \%$, which was much lower than the international standard of ISO 10993; that is, the in vitro hemolysis (HR) experiment should be satisfied. Less than $5 \%$ is in line with the requirements of biomaterial blood testing, so it can be known that the modified SHPCS-AAPSf membrane exhibits better blood compatibility than the unmodified PSf membrane.

APTT, PT and TT. APTT, TT and PT assays are widely used for the clinical screening of plasma abnormalities and the preliminary screening of anticoagulant drugs. Studies usually apply them to evaluate the in vitro antithrombotic ability of biological materials. APTT reflects the role of prothrombin, fibrinogen, factor $\mathrm{V}$, and factor $\mathrm{X}$ in the endogenous coagulation pathway in blood and can be used to measure the efficacy of endogenous coagulation pathways. The TT blood test measures the thrombus formation time of plasma that has been added to thrombin and is often used as an in vitro plasma thrombin time measurement. PT is commonly used to evaluate exogenous coagulation pathways. The results of APTT, TT, and the PT of PSf, AA-PSf, and SHPCS-AA-PSf are shown in Fig. 9(c).
The difference in APTT, TT, and PT between the PSf (36.90 s, $18.10 \mathrm{~s}$, and $11.80 \mathrm{~s})$ and AA-PSf membrane $(38.20 \mathrm{~s}, 18.90 \mathrm{~s}$ and $12.00 \mathrm{~s}$ ) is slight. Compared with the unmodified membrane, the APTT of the modified equivalent was extended by $1.3 \mathrm{~s}$, and the changes of TT and PT were $0.8 \mathrm{~s}$. The APTT, TT, and PT measured by the heparin-like substance SHPCS in this experiment were $179 \mathrm{~s}, 62.10 \mathrm{~s}$, and $29.20 \mathrm{~s}$, respectively. These three data far exceeded the medical test reference values, indicating that SHPCS has a good anticoagulation effect. It can be seen from Fig. 8(c) that the APTT and TT of the modified SHPCS-AAPSf membrane are larger than the corresponding values of the unmodified PSf membrane and that the PT does not change much. This is due to the grafting of the heparin-like substance SHPCS with anticoagulant properties, thereby affecting the endogenous coagulation pathway, which explains to some extent how the modified membrane also has an anticoagulant effect.

\section{Antibacterial test}

In order to study the antibacterial properties of the modified PSf membrane, the antibacterial activity of all samples was tested using Pseudomonas aeruginosa, and the results are shown in Fig. 10. The logarithmic concentration of the bacterial between

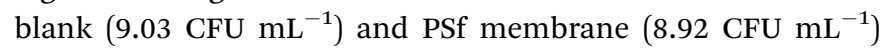


showed nearly no significant difference. The AA-PSf membrane and SHPCS-AA-PSf membrane, the values reduced to 8.75 CFU $\mathrm{mL}^{-1}$ and 6.47 CFU $\mathrm{mL}^{-1}$, respectively. Compared to the pristine membrane, SHPCS-AA-PSf membrane showed good antibacterial properties property.

\section{Conclusion}

Hemocompatible PSf membranes with good anticoagulation and antifouling properties were prepared via covalently grafting acrylic acid and SHPCS. The - $\mathrm{COOH}$ group was successfully grafted onto the surface of the PSf membrane, and SHPCS was also successfully grafted onto the AA-PSf membrane surface in a highly efficient and convenient method, which was confirmed by ATR-FTIR and XPS. The SEM images showed that the membrane after modification exhibited an asymmetric fingerlike pore structure, proving that the modification process had no impact on the structure of the pristine membrane. What's more, the hydrophilicity of the membrane improved to a great extent after grafting SHPCS, as confirmed by the water contact angle decreasing from $86^{\circ}$ to $22^{\circ}$, and all modified membranes displayed higher blood compatibilities than the pristine PSf membranes, such as lower protein adsorption, suppressed platelet adhesion and deformation, decreased hemolysis ratio as well as prolonged PRT and APTT. In summary, an efficient method was researched to modify the pristine PSf membrane, and the SHPCS-AA-PSf membrane showed great potential to be used as a hemocompatible material, especially in hemodialysis.

\section{Conflicts of interest}

The authors declare no conflicts of interest.

\section{Acknowledgements}

This research was supported by the National Natural Science Foundation of China (Project 21476265). We also thank all of our laboratory members for their generous help, especially for the collection of fresh human blood, and gratefully acknowledge the help of Dr R. Wu of the Fourth Hospital of Changsha for the hemocompatibility tests.

\section{References}

1 C. Zhao, et al., Modification of polyethersulfone membranesA review of methods, Prog. Mater. Sci., 2013, 58(1), 76-150.

2 S. K. Bowry, E. Gatti and J. Vienken, Contribution of Polysulfone Membranes to the Success of Convective Dialysis Therapies, Contrib. Nephrol., 2011, 173(173), 110118.

3 S. Senthilkumar, et al., Preparation, Characterization, and Performance Evaluation of Poly(ether-imide) Incorporated Cellulose Acetate Ultrafiltration Membrane for Hemodialysis, Sep. Sci. Technol., 2013, 48(1), 66-75.

$4 \mathrm{~T}$. Knoell, et al., Biofouling potentials of microporous polysulfone membranes containing a sulfonated polyetherethersulfone/polyethersulfone block copolymer: correlation of membrane surface properties with bacterial attachment, J. Membr. Sci., 1999, 157(1), 117-138.

5 H. Qing, L. Qi-Zhao, C. Zhe, et al., The Effect of Electrolyte Concentration on Electrochemical Impedance for Evaluating Polysulfone Membranes, Environ. Sci.: Water Res. Technol., 2018, 4(8), 1145-1151.

$6 \mathrm{M}$. Irfan and A. Idris, Overview of PES biocompatible/ hemodialysis membranes: PES-blood interactions and modification techniques, Mater. Sci. Eng., C, 2015, 56, 574592.

7 Y. T. Chung, E. Mahmoudi and A. W. Mohammad, Development of polysulfone-nanohybrid membranes using ZnO-GO composite for enhanced antifouling and antibacterial control, Desalination, 2017, (402), 123-132.

$8 \mathrm{~J}$. Deng, et al., Switching biological functionalities of biointerfaces via dynamic covalent bond, J. Mater. Chem. B, 2016, 4(4), 694-703.

9 M. Shao, R. Wang, W. Zhao, et al., Facile Fabrication of Mussel-Inspired Multifunctional Polymeric Membranes with Remarkable Anticoagulant, Antifouling, and Antibacterial Properties, Macromol. Mater. Eng., 2018, 1700378.

10 L. Ma, et al., Substrate-Independent Robust and HeparinMimetic Hydrogel Thin Membrane Coating via Combined LbL Self-Assembly and Mussel-Inspired Post-Cross-linking, ACS Appl. Mater. Interfaces, 2015, 7(47), 26050.

11 F. Alali, A. F. Hamdy, A. Hamad, et al., Safety and efficacy of taurolidine/urokinase versus taurolidine/heparin as a tunneled catheter lock solution in hemodialysis patients: a prospective, randomized, controlled study, Nephrol., Dial., Transplant., 2018, 33(4), 619-626.

12 J. Deng, et al., Heparin-Mimicking Multilayer Coating on Polymeric Membrane via LbL Assembly of CyclodextrinBased Supramolecules, ACS Appl. Mater. Interfaces, 2014, 6(23), 21603-21614.

$13 \mathrm{X}$. Fu and J. P. Ning, Synthesis and biocompatibility of an argatroban-modified polysulfone membrane that directly inhibits thrombosis, J. Mater. Sci.: Mater. Med., 2018, 29(5), 66.

$14 \mathrm{H}$. Qin, et al., High efficient protocol for the modification of polyethersulfone membranes with anticoagulant and antifouling properties via in situ cross-linked copolymerization, J. Membr. Sci., 2014, 468(20), 172-183.

15 I. C. Kim, J. G. Choi and T. M. Tak, Sulfonated polyethersulfone by heterogeneous method and its membrane performances, J. Appl. Polym. Sci., 2015, 74(8), 2046-2055.

$16 \mathrm{~L}$. Zhu, et al., Polysulfone hemodiafiltration membranes with enhanced anti-fouling and hemocompatibility modified by poly(vinyl pyrrolidone) via in situ cross-linked polymerization, Mater. Sci. Eng., C, 2017, 74, 159-166.

$17 \mathrm{~F}$. Ran, et al., A simple method to prepare modified polyethersulfone membrane with improved hydrophilic surface by one-pot: The effect of hydrophobic segment length and molecular weight of copolymers, Mater. Sci. Eng., C, 2014, 37(1), 68-75. 
18 S. L. Tomić, J. S. Jovašević and J. M. Filipović, Hemocompatibility, swelling and thermal properties of hydrogels based on 2-hydroxyethyl acrylate, itaconic acid and poly(ethylene glycol) dimethacrylate, Polym. Bull., 2013, 70(10), 2895-2909.

19 I. Sadeghi, et al., Surface modification of polyethersulfone ultrafiltration membranes by corona air plasma for separation of oil/water emulsions, J. Membr. Sci., 2013, 430(3), 24-36.

20 A. M. Laradji, C. D. McNitt, N. S. Yadavalli, V. V. Popik and S. Minko, Robust, solvent-free, catalyst-free click chemistry for the generation of highly stable densely grafted poly(ethylene glycol) polymer brushes by the grafting to method and their properties, Macromolecules, 2016, 49(20), 7625-7631.

21 M. Tang, et al., Heparin-like surface modification of polyethersulfone membrane and its hemocompatibility, $J$. Colloid Interface Sci., 2012, 386(1), 428-440.

22 M. S. Islam, et al., Vitamin E-Coated and Heparin-Coated Dialyzer Membranes for Heparin-Free Hemodialysis: A Multicenter, Randomized, Crossover Trial, Am. J. Kidney Dis., 2016, 68(5), 752-762.

23 G. Zhi, Y. Xue, C. Boo, et al., Self-cleaning anti-fouling hybrid ultrafiltration membranes via side chain grafting of poly(aryl ether sulfone) and titanium dioxide, J. Membr. Sci., 2017, 529, 1-10.

24 Z. Jianhua, T. Fangdong, H. Linfeng, et al., Facile synthesis and properties of a cation exchange membrane with bifunctional groups prepared by pre-irradiation graft copolymerization, RSC Adv., 2018, 8(46), 25966-25973.

25 I. Stepniak, M. Galinski, K. Nowacki, et al., A novel chitosan/ sponge chitin origin material as a membrane for supercapacitors - preparation and characterization, RSC Adv., 2016, 6(5), 4007-4013.

26 R. Jayakumar, et al., Biomaterials based on chitin and chitosan in wound dressing applications, Biotechnol. Adv., 2011, 29(3), 322.

27 H. H. Shuai, C. Y. Yang, I. C. Harn, et al., Using surfaces to modulate the morphology and structure of attached cells a case of cancer cells on chitosan membranes, Chem. Sci., 2013, 4(8), 3058.

28 M. C. Yang and W. C. Lin, The Grafting of Chitosan Oligomer to Polysulfone Membrane via Ozone-Treatment and its Effect on Anti-Bacterial Activity, J. Polym. Res., 2002, 9(2), 135-140.

29 F. Kara, et al., Synthesis and surface modification of polyurethanes with chitosan for antibacterial properties, Carbohydr. Polym., 2014, 112(112), 39-47.
30 T. M. Liu, X. Z. Wu and Y. R. Qiu, Enhanced hemocompatibility and antibacterial property of polyurethane materials modified with citric acid and chitosan, J. Biomater. Sci., Polym. Ed., 2016, $27(12), 1211$.

$31 \mathrm{M}$. Huo, et al., Synthesis and characterization of low-toxic amphiphilic chitosan derivatives and their application as micelle carrier for antitumor drug, Int. J. Pharm., 2010, 394(1-2), 162-173.

32 B. Fang and T. Jiang, Study on the Preparation of Hydroxy Ethyl Chitosan Sulfate, Chin. J. Biochem. Pharm., 1998, 19(4), 163-166.

33 T. M. Liu, J. J. Xu and Y. R. Qiu, A novel kind of polysulfone material with excellent hemocompatibility modified by the sulfonated hydroxypropyl chitosan, Mater. Sci. Eng., C, 2017, 79, 570.

34 X. Tian and Y. R. Qiu, 2-Methoxyethylacrylate modified polysulfone membrane and its blood compatibility, Arch. Biochem. Biophys., 2017, 631.

35 S. Sano, K. Kato and Y. Ikada, Introduction of functional groups onto the surface of polyethylene for protein immobilization, Biomaterials, 1993, 14(11), 817-821.

36 L.-P. Zhu, H.-B. Dong, X.-Z. Wei, Z. Yi, B.-K. Zhu and Y.-Y. Xu, Tethering hydrophilic polymer brushes onto PPESK membranes via surface-initiated atom transfer radical polymerization, J. Membr. Sci., 2008, 320, 407-415.

37 J. Zhang, Platelet adhesive resistance of segmented polyurethane membrane surface grafted with vinyl benzyl sulfo monomer of ammonium zwitterions, Biomaterials, 2003, 24, 4223-4231.

38 A. Tiraferri, Y. Kang, E. P. Giannelis and M. Elimelech, Superhydrophilic thin-membrane composite forward osmosis membranes for organic fouling control: fouling behavior and antifouling mechanisms, Environ. Sci. Technol., 2012, 46(20), 11135-11144.

39 Y. Haishima, C. Hasegawa, Y. Nomura, et al., Development and performance evaluation of a positive reference material for hemolysis testing, J. Biomed. Mater. Res., Part $B, 2014,102(8), 1809-1816$.

40 P. S. Liu, Q. Chen, S. S. Wu, J. Shen and S. C. Lin, Surface modification of cellulose membranes with zwitterionic polymers for resistance to protein adsorption and platelet adhesion, J. Membr. Sci., 2010, 350(1-2), 387-394.

$41 \mathrm{~J}$. Li, B. Zhu, Y. Shao, et al., Construction of anticoagulant poly (lactic acid) membranes via surface covalent graft of heparin-carrying microcapsules, Colloids Surf., B, 2009, 70(1), 15-19. 